\title{
Sabit Yataklı Kolonda Şeftali Çekirdeği Kabuğu Kullanılarak Sulu Çözeltilerden Basic Yellow 51'in Giderimi
}

\author{
İbrahim POLAT ${ }^{1}$, Ramazan ORHAN ${ }^{2 *}$ \\ ${ }^{1}$ Fırat Üniversitesi, Mühendislik Fakültesi, Kimya Mühendisliği Bölümü, Elazığ \\ ${ }^{2}$ Frrat Üniversitesi, Mühendislik Fakültesi, Kimya Mühendisliği Bölümü, Elazığ \\ ${ }^{1} 152118102 @$ firat.edu.tr, ${ }^{* 2}$ rorhan@ firat.edu.tr
}

(Geliş/Received: 04/08/2019;

Kabul/Accepted: 23/08/2019)

\begin{abstract}
Öz: Sabit yataklı kolon sisteminde sulu çözeltiden Basic Yellow 51 (BY51) boyar maddesinin uzaklaştırılması için tarımsal bir atık olan şeftali çekirdeği kabuğu adsorbent olarak kullanılmıştır. Adsorbentin adsorpsiyon özellikleri üzerine başlangıç BY51 boyar madde konsantrasyonu (20-60 mg/L), akıs hızı $(5-10 \mathrm{~mL} / \mathrm{dk})$ ve adsorbent miktarının (1.5-2.5 g) etkisi incelendi. Veriler, breakthrough (kırılma) eğrilerinin akış hızına, başlangıç boyar madde konsantrasyonuna ve adsorbent miktarına bağlı olduğunu gösterdi. En fazla adsorpsiyon kapasitesi $28.12 \mathrm{mg} / \mathrm{g}$ olarak $60 \mathrm{mg} / \mathrm{L}$ BY51 boyar madde konsantrasyonu, 5 $\mathrm{mL} / \mathrm{dk}$ 'lık çözelti akış hızı ve $2.0 \mathrm{~g}$ adsorbent miktarında elde edildi. Thomas ve Yoon-Nelson modelleri kırılma eğrilerini tahmin etmek için elde edilen deneysel verilere başarılı bir şekilde uygulandı.
\end{abstract}

Anahtar kelimeler: Şeftali çekirdeği kabuğu, Bazik sarı 51, Sabit yataklı kolon, Kırılma eğrisi.

\section{Removal of Basic Yellow 51 from Aqueous Solutions Using Peach Stone Shell in Fixed Bed Column}

\begin{abstract}
In the fixed bed column system, the peach stone shell, which is an agricultural waste was used as adsorbent for the removal of Basic Yellow 51 (BY51) dye from the aqueous solution. The effects of initial BY51 dye concentration (20-60 mg / $\mathrm{L})$, flow rate $(5-10 \mathrm{~mL} / \mathrm{min})$ and adsorbent amount (1.5-2.5 g) on the adsorption properties of the adsorbent were examined. Data showed that breakthrough curves were dependent on flow rate, initial dye concentration and adsorbent amount. The highest adsorption capacity was obtained as $28.12 \mathrm{mg} / \mathrm{g}$ at the initial dye concentration of $60 \mathrm{mg} / \mathrm{L}$, the solution flow rate of $5 \mathrm{~mL} / \mathrm{min}$ and the adsorbent amount of $2.0 \mathrm{~g}$. The Thomas and Yoon-Nelson models were successfully applied to the experimental data obtained to estimate the breakthrough curves.
\end{abstract}

Key words: Peach stone shell, Basic Yellow 51, Fixed-bed column, Breakthrough curve.

\section{Giriş}

Boyar madde içeren atık suların arıtılmadan doğal su ortamlarına boşaltılması en önemli çevresel sorunlardan biridir. Boyar maddeler, tekstil, kağıt, kozmetik, plastik ve gıda dahil olmak üzere çeşitli endüstri alanlarında yaygın olarak kullanılan karmaşık aromatik yapılara sahip sentetik kimyasal bileşiklerdir [1]. Bu yapıları onları daha stabil yapar ve biyolojik olarak parçalanmalarını zorlaştırır. Sudaki bu sentetik boyar maddelerin varlığı, insan üzerindeki toksik ve mutajenik etkileri nedeniyle insan sağlığı ve çevre için oldukça zararlıdır [2]. Düşük konsantrasyonda $(1 \mathrm{ppm})$ bile boyar maddeler oldukça belirgin olabilir ve estetik kirlenmeye ve ekosistem ve su kaynaklarında bozulmaya neden olabilir [3]. Bu nedenle, endüstriyel atıklar deşarj edilmeden önce boyarmaddelerin uzaklaştırılması gereklidir.

Atık su arıtımında, boyar maddeleri uzaklaştırmak için fotokatalitik bozunma [4], membran ayırma [5], kimyasal oksidasyon [6], adsorpsiyon [7] ve elektrokimyasal işlem gibi çeşitli yöntemler kullanılmaktadır. Bu boyar madde giderim yöntemleri arasında adsorpsiyon işlemi, hem farklı tip renklendirme maddelerinin giderilmesinde kullanılabileceği için iyi sonuçlar verir [7] hem de yüksek verimliliği, esnekliği, tasarım basitliği, kolay kullanımı ve ekonomik uygulanabilirliği gibi avantajlarından dolayı daha çok kullanılan bir yöntemdir [8]. Aktif karbon, etkili bir adsorbenttir ve boyar maddelerin arıtılmasında yaygın olarak kullanılmaktadır. Ancak, bu adsorbent, yüksek maliyeti nedeniyle pratikte sınırlı kalmıștır. Bu nedenle, ucuz ve etkili alternatif malzemeler çevre bilimcileri için büyük ilgi kaynağı olmuştur. Şimdiye kadar, sulu çözeltilerden boyar madde uzaklaştırılması için çeşitli doğal adsorbentler kullanılmıştır [9]. Adsorbent olarak kullanılan kırsal ürünler hurma çekirdeği lifi [10], pirinç kabuğu [11], talaş [12], yer fistığı kabuğu [10], yağsız jojoba [13], şeker pancarı küspesi [14] vs.'dir. Şeftali (Prunus persica L. Batsch) ülkemizde ve dünyada pek çok ülkede yetişen sert çekirdekli bir meyvedir.

* Sorumlu Yazar: rorhan @ firat.edu.tr. Yazarların ORCID Numarası: ${ }^{10000-0002-6437-228 X,{ }^{2} 0000-0003-2287-4238}$ 
Meyvesi yendikten sonra kalan çekirdekli kısım önemli bir pratik faydası olmadığı için potansiyel bir atıktır. Şeftali çekirdeği kabuğunun boyar madde gideriminde biyosorbent olarak kullanılması, hem çevresel hem de ekonomik açıdan önemli bir alternatiftir.

Bu deneysel çalışmada; boyar madde gideriminde bolluğu, kullanılabilirliğii, çevre dostu ve maliyet açısından daha ekonomik bir biyosorbent olan şeftali çekirdeği kabuğu kullanılmıştır. Bunun için, sabit yataklı kolonda adsorpsiyon ile Basic Yellow 51 (BY51) boyar maddesinin giderimi üzerine adsorbent miktarı, çözelti akış hızı ve başlangıç BY51 boyar madde konstrasyonu gibi farklı çalışma parametreleri ile breakthrough eğrilerini belirlemek için bir seri kolon deneyleri gerçekleştirilmiştir. Elde edilen deneysel verilerin Thomas ve Yoon-Nelson modeline uygunluğu araştırılmış ve modellerin dinamik kinetik parametreleri belirlenmiştir.

\section{Materyal ve Yöntem}

\subsection{Materyaller}

Bu çalışmada adsorbent olarak -50+100 mesh tane boyutuna öğütülmüşşeftali çekirdeği kabuğu (Şekil 1), boyar madde olarak da katyonik bir boyar madde olan Basic Yellow 51 (BY51) kullanıldı. Boyar madde DyStar firmasından temin edildi ve saflaştırma işlemi yapılmadan kullanıldı. Boyar maddenin yapısı ve özellikleri Tablo 1 'de verilmektedir.

Deneylerde kullanılan BY51 boyar maddesinin stok çözeltisi, $1000 \mathrm{mg}$ 'lık boyar madde tartılıp 1 L damıtılmış suda çözündürülmesiyle $1 \mathrm{~g} / \mathrm{L}(1000 \mathrm{ppm})$ derişiminde hazırlandı. Farklı başlangıç boyarmadde konsantrasyonlarında (20-60 mg/L) boyar madde çözeltisi, stok boyar madde çözeltisinden gerekli seyreltmeler yapılarak hazırlandı. Çözeltilerin pH'sını ayarlamak için $0.1 \mathrm{M} \mathrm{HCl}$ ve $0.1 \mathrm{M} \mathrm{NaOH}$ çözeltisi kullanıldı.
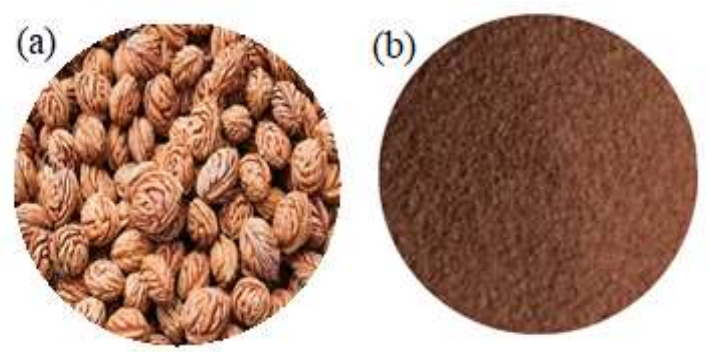

Şekil 1. Şeftali çekirdeği (a), -50+100 mesh öğüülmüş şeftali çekirdeği kabuğu (b)

Tablo 1. BY51'in Özellikleri

\begin{tabular}{|c|c|c|c|c|}
\hline Boyar madde & Kimyasal yapısı & Molekül Ağırlığı (g/mol) & Kimyasal formulü & $\lambda_{\max }(\mathbf{n m})$ \\
\hline Basic Yellow 51 & & 403.5 & $\mathrm{C}_{20} \mathrm{H}_{25} \mathrm{~N}_{3} \mathrm{O}_{4} \mathrm{~S}$ & 425 \\
\hline
\end{tabular}

\subsection{Sabit yataklı kolon ve örnek toplama}

Sabit yataklı kolon çalışmaları $30 \pm 2^{\circ} \mathrm{C}$ sıcaklıkta $1.4 \mathrm{~cm}$ iç çap ve $22 \mathrm{~cm}$ uzunluğundaki soğutma ceketli cam kolonda gerçekleştirildi (Şekil 2). Adsorbent, alt ve üst kısımdan cam yünü ile destekli bir şekilde kolona yerleştirildi. BY51 boyar madde çözeltisinin 20-60 mg/L konsantrasyonundaki çözeltisi kolona alt kısımdan Watson Marlow 120S marka peristaltik pompa ile istenilen akış hızında $(5-10 \mathrm{~mL} / \mathrm{dk})$ breakthrough eğrisi oluşturulana kadar beslendi ve daha sonra kolonun üst kısmından numuler alınarak analiz yapıldı. Örneklerin pH'sı Adwa 1030 Model pH metre kullanılarak ölçüldü. Elde edilen süzüntülerdeki boyar madde analizi Bausch and Lomb Spektronik 20 spektrofotometresi kullanılarak yapıldı. 


\subsection{Kolon veri analizi}

Sabit yataklı, sürekli sistem adsorpsiyon kolonlarında kolonun adsorpsiyon verimi Breakthrough (kırılma) eğrileri vasıtasıyla hesaplanır. Kırılma eğrisi, verilen yatak yüksekliği için, çıkış hacmi veya zamanın fonksiyonu olarak $\mathrm{C}_{\mathrm{t}}$ (çıkış konsantrasyonu)/ $\mathrm{C}_{\mathrm{o}}$ (giriş konsantrasyonu) oranının değişimi olarak tanımlanır. Çıkış hacmi ( $\left.\mathrm{V}_{\mathrm{eff}}\right)$ Denklem 1 kullanılarak bulunur [15].

$\mathrm{V}_{\text {eff }}=\mathrm{Q} \cdot \mathrm{t}_{\mathrm{top}}$

Burada; Q, hacimsel akıș hızı(mL/dk), $t_{\text {top }}$ ise toplam adsorpsiyon süresini göstermektedir. Kırılma eğrisinin altında kalan alan toplam adsorbe edilmiş adsorbat miktarını verir. Kolonda toplam adsorplanan boyar madde miktarı ise Denklem 2 kullanılarak hesaplanır [16].

$\mathrm{q}_{\text {top }}=\frac{\mathrm{Q}}{1000} \int_{\mathrm{t}=0}^{\mathrm{t}=\mathrm{t}_{\text {top }}} \mathrm{C}_{\mathrm{ad}} \mathrm{dt}$

Kolona gönderilen toplam boyar madde miktarı ise Denklem 3 yardımıyla hesaplanır [17].

$\mathrm{m}_{\text {top }}=\frac{\mathrm{C}_{0} * \mathrm{Q} * \mathrm{t}_{\mathrm{top}}}{1000}$

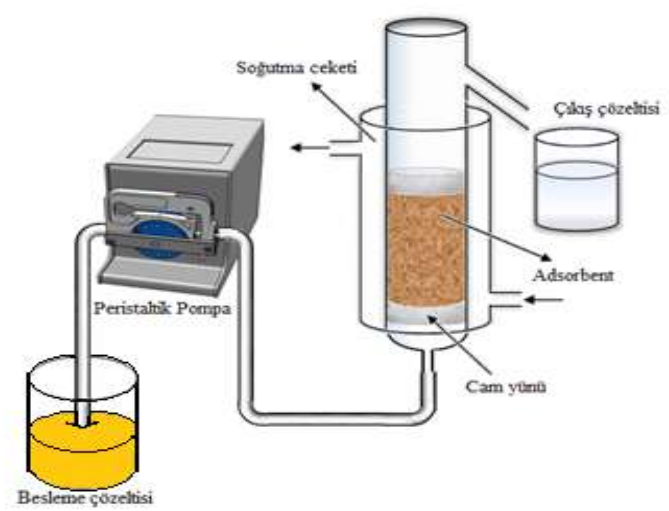

Şekil 2. Deney sisteminin şematik gösterimi

Akış hacmine göre kirleticinin ayrılma yüzdesi yani kolon performansı, toplam adsorbe edilen boyar madde miktarının kolona gönderilen adsorbat miktarına oranından bulunur (Denklem 4) [17].

$\%$ Giderim $=\frac{\mathrm{q}_{\mathrm{top}}}{\mathrm{m}_{\mathrm{top}}} \times 100=\left(1-\frac{C_{e}}{C_{0}} \times 100\right)$

Kolonda, dengeye ulaştığında uzaklaştırılan boyar madde miktarı (maximum kolon kapasitesi) qdenge Denklem 5'deki bağıntı ile hesaplanır [16].

$\mathrm{q}_{\mathrm{denge}}=\frac{\mathrm{q}_{\text {top }}}{\mathrm{m}}$

Burada m, adsorbentin miktarını (g) göstermektedir.

\subsection{Kolon çalışmasının modellenmesi}

Thomas ve Yoon-Nelson gibi matematiksel modeller, sabit yatak kolonunda kirleticilerin uzaklaştırılmasının dinamik davranışını tanımlamak için en çok kullanılanlardır. Bu nedenle, bu modeller çeşitli koşullar altında şeftali çekirdeği kabuğu kullanılarak BY51'in adsorpsiyonu için deneysel verilere uygulanmıştır.

\subsubsection{Thomas modeli}

Bir adsorbentin maksimum adsorpsiyon kapasitesinin değeri, sabit yataklı adsorpsiyon kolonu tasarlanırken önemlidir. Thomas modeli [18] kolon performansını ortaya koymak için geliştirilmiş en yaygın olarak kullanılan modeldir ve doğrusallaştırılmış şekli aşağıdaki gibi ifade edilir.

$\ln \left(\frac{\mathrm{C}_{0}}{\mathrm{C}_{\mathrm{t}}}-1\right)=\frac{\mathrm{k}_{\mathrm{Th}} \mathrm{q}_{0} \mathrm{~m}}{\mathrm{Q}}-\mathrm{k}_{\mathrm{Th}} \mathrm{C}_{0} \mathrm{t}$ 
Burada, $\mathrm{k}_{\mathrm{TH}}$, Thomas hız sabiti (mL/mg dk); $\mathrm{q}_{\mathrm{o}}$, Adsorbentin maksimum adsorpsiyon kapasitesi (mg/g); m, Kolondaki adsorbentin kütlesi (g); Q, Akış hızı (mL/dk). Thomas hız sabiti $\mathrm{k}_{\mathrm{TH}}$ ve adsorbentin maksimum adsorpsiyon kapasitesi $\mathrm{q}_{\mathrm{o}}$ değerleri, farklı deneysel şartlarda t'ye karşı $\ln \left[\left(\mathrm{C}_{\mathrm{o}} / \mathrm{C}_{\mathrm{t}}\right)-1\right]$ grafiğe geçirilerek elde edilen doğrunun eğim ve kaymasından belirlenmektedir.

\subsubsection{Yoon-Nelson Modeli}

Yoon ve Nelson tarafından yapılan araştırmalar sonucunda gazların ve buharların aktif kömür üzerindeki adsorpsiyonu ve kırılma eğrilerinin davranışı için basit bir model geliştirilmiştir. Bu model, her bir adsorbat molekülü için adsorpsiyon sistemindeki azalma hızının adsorbentteki adsorbat atılımı ve adsorbat adsorpsiyonu ile orantılı olduğu varsayımına dayanmaktadır [19]. Tek bileşenli sistem için bu modelin doğrusallaştırılmış şekli aşağıdaki gibi ifade edilmiştir:

$\ln \left(\frac{\mathrm{C}_{\mathrm{t}}}{\mathrm{C}_{0}-\mathrm{C}_{\mathrm{t}}}\right)=\mathrm{k}_{\mathrm{YN}} \mathrm{t}-\tau \mathrm{k}_{\mathrm{YN}}$

Burada, kYN , Hız sabiti (1/dk); $\tau$, \%50 BY51 kırılma eğrisi için gerekli zaman (dk); tb , kırılma zamanı (dk). $t^{t}$ ye karşı $\ln \left[\left(\mathrm{Ct} /\left(\mathrm{C}_{0}-\mathrm{C}_{\mathrm{t}}\right)\right]\right.$ arasında çizilen doğrunun kesim noktasından $\tau$ ve eğiminden ise $\mathrm{k}_{\mathrm{YN}}$ değerleri bulunmaktadır.

\subsection{Hata analizi}

En uygun izoterm modelini belirlemek için, deneysel verilerle izoterm modelinden hesaplanan değerler arasındaki farkı hesaplamak için hata analizi yapılmıştır. Hata analizi için bağıl matematiksel formül [20]:

$\mathrm{SE}=\sqrt{\frac{\sum\left(\mathrm{y}_{\mathrm{d}}-\mathrm{y}_{\mathrm{h}}\right)^{2}}{\mathrm{~N}}}$

Burada, $y_{d}$ ve $y_{h}$, sırasıyla deneysel ve modele göre hesaplanan değerler ve $\mathrm{N}$ deneysel verilerin sayısıdır. Elde edilen istatistiksel parametreler göz önüne alındığında, en yüksek korelasyon katsayısı ( $R^{2}$ değeri 1.0'e yakın) ve en düşük standart hata değerlerini (SE) dikkate alarak uygun model belirlendi.

\section{Sonuçlar ve Tartışma}

\subsection{Başlangıç BY51 konsantrasyonunun etkisi}

BY51 adsorpsiyonu üzerine başlangıç boyar madde konsantrasyonunun etkisi 20, 40 ve $60 \mathrm{mg} / \mathrm{L}$ arasında değişen konsantrasyonlarda incelenmiştir. Adsorbent miktarı $2.0 \mathrm{~g}$ ve akış hızı $8 \mathrm{~mL} / \mathrm{dk}$ olarak sabit tutuldu. Elde edilen deney sonuçları Şekil 3'de verilmiştir. Başlangıç BY51 konsantrasyonu 20'den $60 \mathrm{mg} / \mathrm{L}$ 'ye arttığında, kırılma zamanı ( $\mathrm{t}_{\mathrm{b}}$ ) 65 'ten 25 dk'ya azalmıştır (Tablo 2). Şekil 3'de görüldüğü gibi BY51 boyar maddesinin düşük giriş konsantrasyonları için, kırılma eğrisi daha geç meydana geldi ve adsorbentin yüzeyi daha uzun bir süre sonra BY51 boyar maddesi ile doygunluğa ulaştı, oysa daha yüksek BY51 konsantrasyonu için, kısa bir sürede kırılma eğrisi meydana geldi. Bu durum, difüzyon katsayısı veya kütle transfer katsayısındaki azalmadan dolayı, düşük konsantrasyon gradyentinin daha yavaş bir taşınıma neden olduğu gerçeği ile açıklanabilir [21].

Tablo 2. Farklı giriş BY51 konsantrasyonlarında, adsorbent miktarlarında ve akış hızlarında elde edilen kolon veri parametreleri.

\begin{tabular}{cccccccccc}
\hline $\begin{array}{c}\mathrm{C}_{\mathrm{o}} \\
(\mathrm{mg} / \mathrm{L})\end{array}$ & $\begin{array}{c}\mathrm{Q} \\
(\mathrm{mL} / \mathrm{dk})\end{array}$ & $\begin{array}{c}\mathrm{m} \\
(\mathrm{g})\end{array}$ & $\begin{array}{c}\mathrm{t}_{\mathrm{b}} \\
(\mathrm{dk})\end{array}$ & $\begin{array}{c}\mathrm{t}_{\text {toplam }} \\
(\mathrm{dk})\end{array}$ & $\begin{array}{c}\mathrm{m}_{\text {toplam }} \\
(\mathrm{mg})\end{array}$ & $\begin{array}{c}\mathrm{q}_{\text {toplam }} \\
(\mathrm{mg})\end{array}$ & $\begin{array}{c}\mathrm{q}_{\mathrm{e}, \text { denge }} \\
(\mathrm{mg} / \mathrm{g})\end{array}$ & $\begin{array}{c}\mathrm{V}_{\text {eff }} \\
(\mathrm{mL})\end{array}$ & $\begin{array}{c}\% \\
\text { Giderim }\end{array}$ \\
\hline $\mathbf{2 0}$ & 8 & 2.0 & 65 & 620 & 99.20 & 33.35 & 16.67 & 4960 & 33.62 \\
$\mathbf{4 0}$ & 8 & 2.0 & 50 & 465 & 148.80 & 50.74 & 25.37 & 3720 & 34.10 \\
$\mathbf{6 0}$ & 8 & 2.0 & 25 & 330 & 158.40 & 56.24 & 28.12 & 2640 & 35.51 \\
40 & $\mathbf{5}$ & 2.0 & 80 & 705 & 141.00 & 53.45 & 26.72 & 3525 & 37.91 \\
40 & $\mathbf{8}$ & 2.0 & 50 & 465 & 148.80 & 50.74 & 25.37 & 3720 & 34.10 \\
40 & $\mathbf{1 0}$ & 2.0 & 25 & 375 & 150.00 & 47.28 & 23.64 & 3750 & 31.52 \\
40 & 8 & $\mathbf{1 . 5}$ & 25 & 345 & 110.40 & 34.71 & 17.35 & 2760 & 31.44 \\
40 & 8 & $\mathbf{2 . 0}$ & 50 & 465 & 148.80 & 50.74 & 25.37 & 3720 & 34.10 \\
40 & 8 & $\mathbf{2 . 5}$ & 75 & 615 & 196.80 & 68.30 & 34.15 & 4920 & 35.00 \\
\hline
\end{tabular}




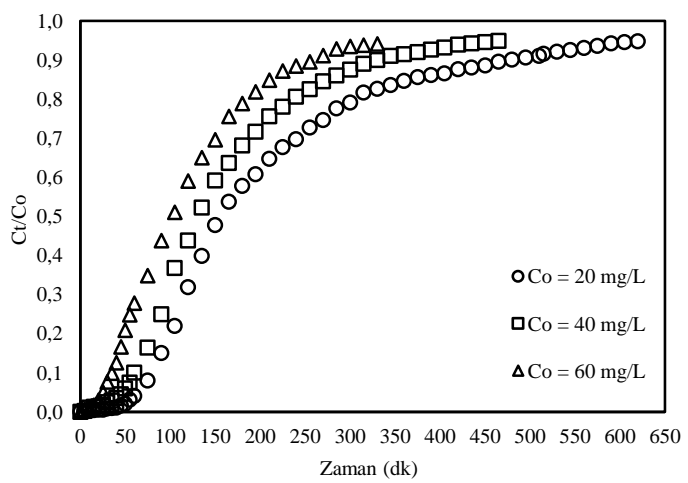

Şekil 3. Kırılma eğrileri üzerine farklı başlangıç konsantrasyonlarının etkisi $\left(\mathrm{Q}=8 \mathrm{~mL} / \mathrm{dk}, \mathrm{m}=2.0 \mathrm{~g}, \mathrm{~T}=30 \pm 2^{\circ} \mathrm{C}\right)$

Başlangıç konsantrasyonu ne kadar büyük olursa, kırılma eğrisinin eğimi daha diktir ve kırılma zamanı daha küçük olur. $\mathrm{Bu}$ sonuçlar, konsantrasyon gradyentindeki değişimin, doygunluk hızını ve kırılma zamanını etkilediğini veya difüzyon işleminin konsantrasyona bağlı olduğunu göstermektedir [22]. Metilen mavisinin pirinç kabuğu tarafindan biyosorpsiyonu için benzer eğilimler elde edilmiştir [23]. Başlangıç boyar madde konsantrasyonunun arttırılması ile adsorpsiyon kapasitesinin artması beklenir çünkü yüksek konsantrasyon farkı adsorpsiyon işlemi için yüksek itici güç sağlar [24]. Başlangıç BY51 boyar madde konsantrasyonunun 20'dan 60 $\mathrm{mg} / \mathrm{L}$ 'ye artması ile denge anında adsorbentin maksimum adsorpsiyon kapasitesi 16.67 'den $28.12 \mathrm{mg} / \mathrm{g}$ 'a arttı̆̆ görüldü.

\subsection{Akıș Hızının Etkisi}

Şeftali çekirdeği kabuğu kullanarak BY51'in adsorpsiyonu üzerine akış hızının etkisi, sabit $40 \mathrm{mg} / \mathrm{L}$ başlangıç BY51 boyar madde konsantrasyonu ve sabit $2.0 \mathrm{~g}$ adsorbent miktarında, farklı akış hızları $(5,8$ ve $10 \mathrm{~mL} / \mathrm{dk})$ ile araştırılmıştır. Deney sonuçları Şekil 4'de gösterilmiştir.

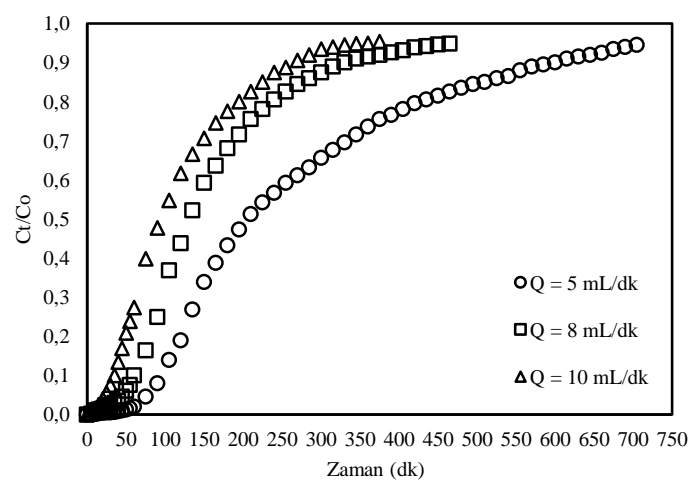

Şekil 4. Kırılma eğrileri üzerine farklı akış hızlarının etkisi $\left(C_{o}=40 \mathrm{mg} / \mathrm{L}, \mathrm{m}=2.0 \mathrm{~g}, \mathrm{~T}=30 \pm 2^{\circ} \mathrm{C}\right)$

Hız arttıkça adsorpsiyon hızını artıran kütle transfer hızı artmıştır. Bu nedenle daha yüksek akış hızlarında erken kırılma eğrileri elde edilmiştir [25]. Akış hızındaki azalma ile doygunluğa ulaşma süresi ve kırılma zamanı önemli ölçüde artmıştır yani akış hızı 5 'den 10 mL/dk'ya çıkartıldığı zaman kırılma zamanı (t azalmıştır ayrıca denge anındaki adsorpsiyon kapasitesi 26.72 'den $23.64 \mathrm{mg} / \mathrm{g}$ 'a düşmüştür (Tablo 2). Bunun nedeni, ve dolayısı ile BY51 boyar madde çözeltisinin daha yüksek akış hızında BY51 iyonları ile adsorbent arasındaki temas süresinin daha az olmasıdır. Daha yüksek akış hızında, kolondaki BY51 çözeltisi daha az kalma süresi ve adsorbentin gözeneklerine daha az difüzyonu nedeniyle adsorpsiyon kapasitesi daha düşük olmuştur ve bu nedenle BY51 boyar madde çözeltisi, denge oluşmadan önce kolondan ayrılmıştır [26].

\subsection{Adsorbent miktarının Etkisi}

$8 \mathrm{~mL} / \mathrm{dk}$ sabit akış hızında ve $40 \mathrm{mg} / \mathrm{L}$ sabit giriş BY51 konsantrasyonunda, $1.5,2.0$ ve $2.5 \mathrm{~g}$ farklı adsorbent miktarlarında şeftali çekirdeği kabuğu üzerine BY51'ün adsorpsiyonu için elde edilen kırılma eğrileri Şekil 5'de 
verilmiştir. Şekil 5 'ten, kırılma eğrisi süresinin artan adsorbent miktarı ile arttığı bulunmuştur. Adsorbent miktarını 1.5'dan 2.5 g'a arttırmak suretiyle kırılma zamanının 25'den 75 dk'ya ve kolonun boyar madde giderme kapasitesinin 17.35'den 34.15 mg/g'a yükseldiği görülmektedir (Tablo 2). Adsorbent miktarı arttıkça, daha fazla giderim verimine sebep olan adsorbent ile BY51 boyar maddesinin kolon içerisinde kalma süresi artmıştır ve kırılma eğrisinin eğimi azalmıştır bu da geniş̧letilmiş bir kütle transfer bölgesinin oluştuğunu gösterir. Adsorpsiyon yüzeyindeki artışa bağlı olarak daha fazla adsorbent miktarında, adsorpsiyon için daha fazla bağlanma yeri oluşturarak yüksek adsorpsiyon kapasiteside gözlenmiştir [27]. Benzer sonuçlar farklı araştırmacılar tarafindan rapor edilmiştir [28,29].

\subsection{Dinamik Adsorpsiyon Modelleri}

\subsubsection{Thomas modeli}

Sabit yataklı kolonda elde edilen veriler, Thomas hız sabitini $\left(\mathrm{K}_{\mathrm{Th}}\right)$ ve maksimum katı faz konsantrasyonunu $\left(\mathrm{q}_{\mathrm{o}}\right)$ hesaplamak için Thomas kinetik modeline uygulanmıştır. Denklem (6)'a göre lineer regresyon analizi kullanılarak belirlenen katsayılar ve bağıl sabitler elde edildi ve sonuçlar Tablo 3 'de verilmiştir.

Tablo 3. Farklı deneysel şartlarda BY51'in Thomas modeli parametreleri

\begin{tabular}{|c|c|c|c|c|c|c|c|}
\hline \multirow{2}{*}{$\mathrm{C}_{\mathrm{o}}(\mathrm{mg} / \mathrm{L})$} & \multirow{2}{*}{$\mathrm{Q}(\mathrm{mL} / \mathrm{dk})$} & \multirow{2}{*}{$\mathrm{m}(\mathrm{g})$} & \multicolumn{3}{|c|}{ Thomas } & \multirow{2}{*}{$\mathrm{R}^{2}$} & \multirow{2}{*}{ SE } \\
\hline & & & $\mathrm{k}_{\mathrm{Th}}(\mathrm{mL} / \mathrm{mg} \mathrm{dk})$ & $\mathrm{q}_{\mathrm{o}}(\mathrm{mg} / \mathrm{g})$ & $\mathrm{q}_{\mathrm{o}, \text { deny. }}(\mathrm{mg} / \mathrm{g})$ & & \\
\hline 20 & 8 & 2.0 & 0.65 & 22.92 & 16.68 & 0.815 & 0.177 \\
\hline 40 & 8 & 2.0 & 0.42 & 33.11 & 25.37 & 0.870 & 0.137 \\
\hline 60 & 8 & 2.0 & 0.35 & 34.47 & 28.12 & 0.875 & 0.100 \\
\hline 40 & 5 & 2.0 & 0.29 & 34.67 & 26.72 & 0.827 & 0.162 \\
\hline 40 & 8 & 2.0 & 0.42 & 33.11 & 25.37 & 0.870 & 0.137 \\
\hline 40 & 10 & 2.0 & 0.45 & 29.42 & 23.64 & 0.882 & 0.106 \\
\hline 40 & 8 & 1.5 & 0.49 & 28.66 & 23.14 & 0.852 & 0.107 \\
\hline 40 & 8 & 2.0 & 0.42 & 33.11 & 25.37 & 0.870 & 0.137 \\
\hline 40 & 8 & 2.5 & 0.35 & 36.76 & 27.32 & 0.817 & 0.171 \\
\hline
\end{tabular}

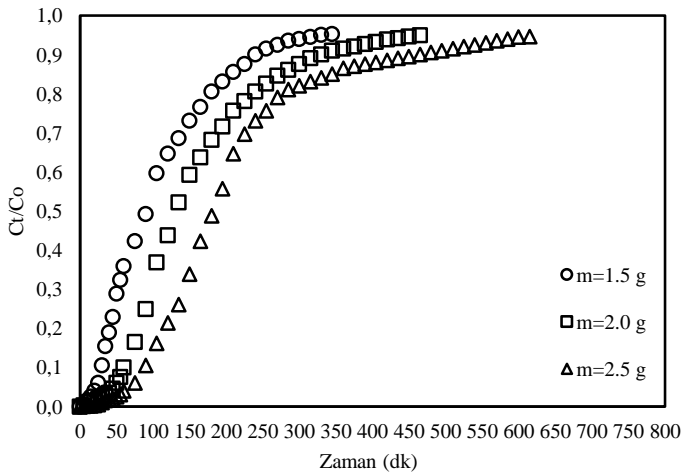

Şekil 5. Kırılma eğrileri üzerine farklı adsorbent miktarlarının etkisi $\left(\mathrm{C}_{\mathrm{o}}=40 \mathrm{mg} / \mathrm{L}, \mathrm{Q}=8 \mathrm{~mL} / \mathrm{dk}, \mathrm{T}=30 \pm 2^{\circ} \mathrm{C}\right)$.

Tablo 3 'ten nispeten düşük lineer regresyon katsayısı değerleri $\left(0.815<\mathrm{R}^{2}<0.882\right)$ ve düşük $\mathrm{SE}(<0.177)$ değerleri bu modelin deneysel verilere çok uyumlu olmamakla birlikte Yoon Nelson modeline göre uyumlu olduğu söylenebilir. Tablo 3'ten görüldüğü gibi, giriş konsantrasyonu arttıkça qo'ın değeri arttı ancak kTh'1n değeri azaldı. Bunun nedeni, adsorpsiyon için itici gücün, adsorbent üzerindeki boyar madde ile çözelti içindeki boyar madde arasındaki konsantrasyon farkıdır [30]. Akış hızı arttışı ile $\mathrm{q}_{\mathrm{o}}$ değeri azaldı, fakat $\mathrm{k}_{\mathrm{Th}}$ değeri arttı. Adsorbent miktarı arttıkça, $\mathrm{k}_{\mathrm{Th}}$ değeri azalırken $\mathrm{q}_{\mathrm{o}}$ değeri önemli ölçüde arttı. Bu nedenle daha düşük akış hızı, daha yüksek giriş konsantrasyonu ve daha fazla adsorbent miktarı şeftali çekirdeği kabuğuna BY51'in adsorpsiyonunu artıracaktır.

\subsubsection{Yoon-Nelson modeli}

Şeftali çekirdeği kabuğu ile BY51'in adsorpsiyonundan elde edilen kolon verileri daha az karmaşık olan

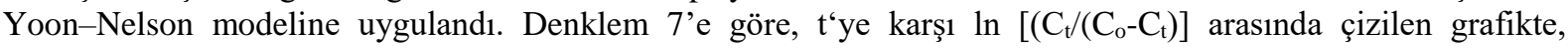


doğrunun kesim noktasından $\tau$ (\% 50 BY51 kırılma eğrisi için gereken süre) ve eğiminden ise Yoon-Nelson sabiti $\left(\mathrm{k}_{\mathrm{YN}}\right)$ değerleri hesaplanarak Tablo 4'de verilmiştir. Nispeten düşük lineer regresyon katsayısı değerleri $\left(0.815<\mathrm{R}^{2}<0.882\right)$ ve yüksek SE (7.663-16.854) değerlerinin Thomas modelinden daha fazla olduğu ve $\tau(\mathrm{dk})$ 'nun hesaplanan değerlerinin deneysel değerlerle eşleşmediği Tablo 4'den görülmektedir. Hem daha yüksek akış hızı hem de başlangıç BY51 boyar madde konsantrasyonu ile daha yüksek kYN değerine ulaşıldığ görülmüştür, ancak daha fazla adsorbent miktarı ile bu değer azalmıştır. Ayrıca, artan akış hızı ve başlangıç BY51 boyar madde konsantrasyonu ile $\tau$ 'nun değeri azalmış, fakat adsorbent miktarı artışı ile artmıştır. Bunun nedeni, başlangıç BY51 boyar madde konsantrasyonunun artmasının, adsorpsiyon bölgesi için boyar madde molekülleri arasındaki rekabeti arttırması ve bunun sonucunda da daha yüksek giderim oranı vermesi olabilir [31].

Regrasyon katsayısı $\left(\mathrm{R}^{2}\right)$ iki model içinde yaklaşık olarak yakın değerler olarak bulunmasına rağmen, hata değerleri (SE) açısından ise sıfıra yakınlık Thomas modelinde bulunmuştur. Yoon-Nelson modelindeki hata değerleri sıfirdan oldukça fazla değer olarak bulunduğundan yani deneysel verilerle modelden bulunan veriler arasında büyük fark oluştuğundan bu modelin bizim deneysel verilere uygun model olmadığını söyleyebiliriz.

Tablo 4. Farklı deneysel şartlarda Yoon-Nelson modeli parametreleri

\begin{tabular}{|c|c|c|c|c|c|c|c|}
\hline \multirow{2}{*}{$\mathrm{C}_{\mathrm{o}}(\mathrm{mg} / \mathrm{L})$} & \multirow{2}{*}{$\mathrm{Q}(\mathrm{mL} / \mathrm{dk})$} & \multirow{2}{*}{$\mathrm{m}(\mathrm{g})$} & \multicolumn{3}{|c|}{ Yoon-Nelson } & \multirow{2}{*}{$\mathrm{R}^{2}$} & \multirow{2}{*}{ SE } \\
\hline & & & $\mathrm{k}_{\mathrm{YN}}(1 / \mathrm{dk})$ & $\tau(\mathrm{dk})$ & $\tau_{\% 50 \text {, deny. }}(\mathrm{dk})$ & & \\
\hline 20 & 8 & 2.0 & 0.013 & 284.00 & 165 & 0.815 & 13.170 \\
\hline 40 & 8 & 2.0 & 0.017 & 200.00 & 135 & 0.870 & 12.312 \\
\hline 60 & 8 & 2.0 & 0.021 & 138.09 & 105 & 0.875 & 7.663 \\
\hline 40 & 5 & 2.0 & 0.012 & 325.00 & 210 & 0.827 & 9.698 \\
\hline 40 & 8 & 2.0 & 0.017 & 200.00 & 135 & 0.870 & 12.312 \\
\hline 40 & 10 & 2.0 & 0.018 & 143.64 & 105 & 0.882 & 9.514 \\
\hline 40 & 8 & 1.5 & 0.020 & 130.00 & 100 & 0.852 & 9.168 \\
\hline 40 & 8 & 2.0 & 0.017 & 200.00 & 135 & 0.870 & 12.312 \\
\hline 40 & 8 & 2.5 & 0.014 & 278.00 & 195 & 0.817 & 16.854 \\
\hline
\end{tabular}

\section{Sonuçlar}

$\mathrm{Bu}$ çalışma, yerel olarak ve bol miktarda mevcut bir tarımsal atık olan şeftali çekirdeği kabuğunun, sulu çözeltiden BY51 boyar maddesinin uzaklaştırılması için ticari aktif karbona alternatif etkili ve çevre dostu bir adsorbent olarak kullanılabileceğini doğrulamıştır. Başlangıç boyar madde konsantrasyonunun adsorbent miktarının ve çözelti akış hızının kırılma eğrileri üzerindeki etkisi incelenmiştir. Elde edilen sonuçlar BY51'in adsorpsiyonunun başlangıç boyar madde konsantrasyonuna, adsorbent miktarına ve akış hızına bağlı olduğunu gösterdi. Sabit yatağın adsorpsiyon kapasitesi akış hızı artışı ile azalmış fakat başlangıç boyar madde konsantrasyonu ve yatak yüksekliği artışı ile artmıştır. Diğer taraftan maksimum kolon kapasitesi $5 \mathrm{~mL} / \mathrm{dk}$ akış hızı, $20 \mathrm{mg} / \mathrm{L}$ başlangıç boyar madde konsantrasyonu ve $1.5 \mathrm{~cm}$ yatak yüksekliği için biyosorbentin gramında yaklaşık 17.07 mg BB3 olarak bulunmuştur. Breakthrough eğrilerini tahmin etmek için sabit yataklı kolonda yapılan dinamik çalışmada elde edilen deneysel verilere Thomas ve Yoon-Nelson modelleri, kolon proses tasarımında gerekli olan kolon kinetik parametrelerinin belirlenmesi amacıyla uygulanmıştır. BB3 biyosorpsiyonu için kolon verilerinin Thomas modeline daha uygun olduğunu göstermiştir.

\section{Kaynaklar}

[1] Yang Y, Wang G, Wang B, Li Z, Jia X, Zhou Q, Zhao Y. Biosorption of Acid Black 172 and Congo Red from aqueous solution by nonviable Penicillium YW 01: kinetic study, equilibrium isotherm and artificial neural network modeling. Bioresour. Technol. 2011; 102: 828-834.

[2] Gupta VK, Mohan D, Sharma S, Sharma M. Removal of basic dyes (rhodamine B and methylene blue) from aqueous solutions using bagasse fly ash. Sep. Sci. Technol. 2000; 35 (13): 2097-2113.

[3] Vimonses V, Jin B, Chow CWK. Insight into removal kinetic and mechanisms of anionic dye by calcined clay materials and lime. J. Hazard. Mater. 2010;177:420-427.

[4] Sohrabi MR, Ghavami M. Photocatalytic Degradation of Direct Red 23 Dye Using UV/TiO 2 : Effect of Operational Parameters. J. Hazard. Mater. 2008; 153 (3): 1235-1239.

[5] Ciardelli G, Corsi L, Marcucci M. Membrane Seperation for Watewater Reuse in the Textile Industry. Resour. Conserv. Recycl. 2001; 31 (2): 189-197.

[6] Tang H, Yin L, Lu H. Synthesis, Conformations and Cell-Penetrating Properties. Biomacromolecules 2012; 13 (9): 2609 2615. 
[7] Rafatullah M, Sulaiman O, Hashim R, Ahmad A. Adsorption of Methylene Blue on Low-cost Adsorbents: A Review. J. Hazard Mater. 2010; 177 (1): 70-80.

[8] Aguedach A, Brosillon S, Morvan J, Lhadi EK. Photocatalytic degradation of azodyes reactive black 5 and reactive yellow 145 in water over a newly deposited titanium dioxide. Appl. Catal. B Environ. 2005; 57: 55-62.

[9] Sharma P, Kaur H, Sharma M, Sahore V. A review on applicability of naturally available adsorbents for the removal of hazardous dyes from aqueous waste. Environ.Monit. Assess. 2011; 183: 151-195.

[10] Altenor S, Ncibi MC, Emmanuel E, Gaspard S. Textural Characteristics, Physiochemical Properties and Adsorption Efficiencies of Caribbean Alga Turbinaria Turbinata and Its Derived Carbonaceous Materials for Water Treatment Application. Biochem. Eng. J. 2012; 1 (67): 35-44.

[11] Malik PK. Use of activated carbons prepared from sawdust and rice-husk for adsorption of acid dyes: a case study of Acid Yellow 36. Dyes Pigments. 2003; 56: 239-249.

[12] Kini SM, Saidutta MB, Murty VRC, Kadoli SV. Adsorption of basic dye fromaqueous solution using $\mathrm{HCl}$ treated saw dust (Lagerstroemia microcarpa): kinetic, modeling of equilibrium, thermodynamic. India, Int. Res. J. Env. Sci. 2013; 2: 6-16.

[13] Al-Anber ZA, Al-Anber MA, Matouq M, Al-Ayed O, Omari NM. Defatted Jojoba for the Removal of Methylene Blue from Aqueous Solution: Thermodynamic and Kinetic Studies. Desalination. 2011; 276 (1): 169-174.

[14] Malekbala M, Hosseini S, Yazdi SK, Masoudi SS. The Study of the Potential Capability of Sugar Beet Pulp on the Removal Efficiency of Two Cationic Dyes. Chem. Eng. Res. Des. 2013; 90 (5): 704-712.

[15] Al-Degs YS, Khraisheh MA, Allen SJ, Ahmad MN. Adsorption characteristics of reactive dyes in columns of activated carbon. J Hazard Mater 2009;165(1-3):944-949.

[16] Aksu Z, Gonen F. Biosorption of phenol by immobilized activated sludge in a continuous packed bed: prediction of breakthrough curves. Process Biochem 2004; 39: 599-613.

[17] Yagub MT, Sen TK, Afroze S, Ang HM. Fixed-bed dynamic column adsorption study of methylene blue (MB) onto pine cone. Desalin Water Treat 2015; 55:1026-1039.

[18] Thomas HC. Heterogeneous ion exchange in a flowing system, J. Am. Chem. Soc. 1944; 66: 1466-1664.

[19] Yoon YH, Nelson J.H. Application of gas adsorption kinetics. I. A theoretical model for respirator cartridge service life. Am. Ind. Hyg. Assoc. J. 1984; 45: 509-516.

[20] Han R, Ding D, Xu Y, Zou W, Wang Y, Li Y, Zou L. Use of rice husk for the adsorption of Congo red from aqueous solution in column mode. Biores. Technol. 2008; 99: 2938-2946.

[21] El-Kamash AM. Evaluation of zeolite A for the sorptive removal of $\mathrm{Cs}^{+}$and $\mathrm{Sr}^{2+}$ ions from aqueous solutions using batch and fixed bed column operations. J Hazard Mater. 2008;151:432-445.

[22] Goel J, Kadirvelu K, Rajagopal C, Garg VK. Removal of lead(II) by adsorption using treated granular activated carbon: batch and column studies, J. Hazard. Mater. B 2005; 125: 211-220.

[23] Han R, Wang Y, Yu W, Zou W, Shi J, Liu H. Biosorption of methylene blue from aqueous solution by rice husk in a fixed-bed column. J. Hazard. Mater. 2007; 141: 713-718.

[24] Sadaf S, Bhatti HN. Evaluation of peanut husk as a novel, low cost biosorbent for the removal of Indosol Orange RSN dye from aqueous solutions: batch and fixed bed studies. Clean Technol Environ Policy 2014;16: 527-544.

[25] Sen TK, Mahajan SP, Khilar KC. Colloid-associated contaminant transport in porous media: 1. Experimental studies. AIChE J 2002; 48: 2366-2374.

[26] Ozdemir O, Turan M, Turan AZ, Faki A, Engin AB. Feasibility analysis of color removal from textile dyeing wastewater in a fixed-bed column system by surfactant-modified zeolite (SMZ). J. Hazard. Mater. 2009; 166: 647-654.

[27] Vijayaraghavan K, Jegan J, Palanivelu K, Velan M. Removal of nickel(II) ions from aqueous solution using crab shell particles in a packed bed up flow column, J. Hazard. Mater. 2004; 113B (1-3): 223-230.

[28] Foroughi-dahr M, Esmaieli M, Abolghasemi H, Shojamoradi A, Pouya ES. Continuous adsorption study of Congo red using tea waste in a fixed-bed column. Desalin. Water Treat 2016; 57: 8437-8446.

[29] Mobasherpour I, Salahi E, Asjodi A. Research on the batch and fixed-bed column performance of red mud adsorbents for lead removal. Canadian Chemical Transactions 2014; 2 (1): 83-96.

[30] Padmesh TVN, Vijayaraghavan K, Sekaran G, Velan M. Batch and column studies on biosorption of acid dyes on fresh water macro alga Azolla filiculoides. J. Hazard. Mater. 2005; B 125: 121-129.

[31] Han RP, Wang Y, Zhao X, Wang YF, Xie FL, Cheng JM, et al. Adsorption of methylene blue by phoenix tree leaf powder in a fixed-bed column: experiments and prediction of breakthrough curves. Desalination 2009;245: 284-297. 